\title{
PRODUÇÃO E CARACTERIZAÇÃO DE FILMES COMESTÍVEIS À BASE DE ALGINATO E PECTINA.
}

\author{
G.D. da SILVA ${ }^{1,2}$, G.O. LOCATELLI ${ }^{1}$, L. FINKLER ${ }^{1}$ e C. L. L. FINKLER ${ }^{1}$ \\ ${ }^{1}$ Universidade Federal de Pernambuco, Centro Acadêmico de Vitória \\ ${ }^{2}$ Universidade Federal de Pernambuco, Pós-graduação em Nutrição. \\ E-mail para contato: gabriel_locatelli@hotmail.com
}

\begin{abstract}
RESUMO - Embalagens comestíveis utilizando matérias-primas renováveis e tecnologias capazes de minimizar os danos ao meio ambiente vêm despertando grande interesse nas últimas décadas. Esses filmes, além de conferirem proteção mecânica e prevenirem a deterioração, possibilitam a agregação de fatores sensoriais e nutricionais aos alimentos. Nesse contexto, estão inseridos os filmes produzidos à base de alginato e pectina. Esses hidrocolóides são reconhecidos como seguros pela FoodandDrugAdministration (FDA) e largamente usados na indústria de alimentos devido às suas propriedades espessantes e geleificantes, destacando-se pelas suas propriedades de barreira à $\mathrm{O}_{2}, \mathrm{CO}_{2}$ e etileno. Diante disto, objetivou-se desenvolver filmes comestíveis à base de alginato e pectina para posterior agregação de micro-organismos probióticos. Para isto foi realizado um planejamento fatorial completo $2^{2}$, tendo como variáveis independentes a proporção de alginato/pectina e a porcentagem de glicerol na primeira reticulação. A reticulação foi realizada em duas etapas: a primeira com $\mathrm{CaCl}_{2} 1 \%$ (p/v) e a segunda com $\mathrm{CaCl}_{2} 5 \%(\mathrm{p} / \mathrm{v})$ mais glicerol $3 \%(\mathrm{p} / \mathrm{v})$, ambas seguidas de secagem em estufa de circulação de ar. Os filmes obtidos apresentaram aspecto plástico e as análises de caracterização indicaram solubilidade em água entre 0,53 e 0,92 g/g de filme seco, após 24 horas de agitação egrau de intumescimento máximo entre 3,15 e 8,85 após 60 minutos de imersão em água destilada.
\end{abstract}

\section{INTRODUÇÃO}

O uso de materiais plásticos nas mais diversas aplicações, principalmente em objetos de rápida circulação, aliados ao descarte inadequado, fez de uma das suas principais características - a durabilidade - a grande causadora de graves danos ambientais. Em decorrência disso, a comunidade científica busca alternativas tecnológicas para esse problema. Nesse cenário, os polímeros biodegradáveis surgemcomo uma alternativa para substituir os polímeros sintéticos derivados do petróleo.A utilização de polímeros de origem biológica na produção de embalagens biodegradáveis pode ser feita de três maneiras: através de mistura de biopolímeros com polímeros sintéticos; biopolímerosbacterianos obtidos por fermentação; e o uso de biopolímerosnaturais diretamente na produção de filmes, como os filmes comestíveis.

Filmes comestíveis são materiais finos e flexíveis elaborados com macromoléculas biológicas capazes de formar uma matriz contínua, podendo conter diferentes aditivos de grau alimentício (TABOADAet al., 2008).A escolha do material a ser utilizado na formulação dos 
filmes e revestimentos deve levar em consideração as interações entre os componentes do material, que poderão levar a alterações nas características do alimento. De maneira geral, esses filmes têm sido caracterizados quanto às suas propriedades funcionais e/ou físicas, com destaque para as propriedades mecânicas, propriedades de barreira (vapor de água, $\mathrm{O}_{2}, \mathrm{CO}_{2} \mathrm{e}$ etileno), solubilidade em água, cor, opacidade, resultando como principais funções a manutenção da qualidade do produto alimentício e o aumento da vida de prateleira(TABOADA et al., 2008). A principal desvantagem desses filmes e revestimentos é a baixa impermeabilidade ao vapor de água, devido à natureza hidrofílica dos polímeros (YANG \& PAULSON, 2000).

Devido à capacidade de formar géis insolúveis quando reagem com cátions multivalentes, alginato e pectina são biopolímeros adequados para uso em filmes e revestimentos,além de serem reconhecidos como seguros pela FoodandDrugAdministration (FDA) e largamente usados na indústria de alimentos. Diversos trabalhos têm proposto o uso desses biopolímeros na formação de filmes e na imobilização de substâncias ativas, podendo ser aplicados de maneira isolada ou como co-polímeros, inclusive com a adição de agentes antimicrobianos, que possuem a função de impedir a contaminação e a deterioração dos alimentos.

A imobilização de agentes probióticos também tem sido estudada, mas são poucos os trabalhos que relacionam a incorporação desses agentes em biofilmes, sendo uma importante e promissora alternativa para aumentar sua disponibilidade na dieta humana. Os probióticos, usados há milhares de anos pelas culturas orientais, vêm despertando o interesse dos consumidores que buscam uma dieta saudável, sendo atribuídos a eles inúmeros benefícios à saúde do consumidor. Nessa categoria é conhecida uma grande diversidade de microorganismos, destacando-se as bactérias pertencentes ao gênero Lactobacillus.Esses microorganismos, além de promoverem benefícios à saúde do consumidor, podem acidificar, conferir aroma, sabor, textura e ainda auxiliarem na bioconservação dos alimentos (BURITI\&SAAD, 2007).

Desta forma, baseados nas propriedades de formação de filmes de alginato e pectina e sua capacidade de imobilizar substâncias, o presente trabalho buscou definir as melhores proporções de alginato/pectina e agente plastificante que possibilitassem a obtenção de filmes com características visuais satisfatórias para a manipulação e com baixa solubilidade em água, e ainda que permitissem a imobilização de micro-organismos probióticos. Filmes probióticos podem ser uma nova alternativa para disponibilizar esses agentes na dieta humana, que dependendo do processo não podem ser aplicados na formulação dos alimentos.

\section{MATERIAIS E MÉTODOS}

A elaboração dos filmes se baseou no método composto de dois estágios, desenvolvido para a elaboração de filmes de alginato de cálcio por Zactiti e Kieckbusch (2005), fazendo-se as devidas modificações visando posteriormenteà inserção dos microorganismosprobióticos. A concentração de biopolímeros $(1,5 \% \mathrm{p} / \mathrm{v})$ e as concentrações de agente reticulante nas duas etapas de reticulaçãoforam definidas com base nos melhores resultados encontrados por Bierhalz (2010). 
Para encontrar a melhor relação de alginato/pectina e a do agente plastificante usado na formulação (glicerol), foi elaborado um planejamento fatorial completo $2^{2}$, com três pontos centrais (nível 0) e quatro axiais (níveis $\pm \alpha$, onde $\alpha=1,4142$ ), totalizando 11 ensaios (Planejamento Composto Central Rotacional - PCCR, Tabela 1). As variáveis estudadas foram a proporção de alginato/pectina e a porcentagem de glicerol na primeira reticulação, tendo como variáveis resposta a solubilidade dos filmes (massa solúvel $\mathrm{g} / \mathrm{g}$ de filme) e o grau de intumescimento atingido após 60 minutos de imersão em água, visando atingir os níveis mínimos dessas variáveis.

Tabela 1 - Níveis codificados e valores reais das variáveis estudadas para o planejamento experimental nos ensaios de elaboração dos filmes

\begin{tabular}{ccc}
\hline Ensaios & $\begin{array}{c}\text { Proporção Alginato / } \\
\text { Pectina (\%) }\end{array}$ & Concentração de Glicerol (\%) \\
\hline 1 & $-1(57,3: 42,7)$ & $-1(0,3)$ \\
2 & $+1(92,7: 7,3)$ & $-1(0,3)$ \\
3 & $-1(57,3: 42,7)$ & $+1(1,7)$ \\
4 & $+1(92,7: 7,3)$ & $+1(1,7)$ \\
5 & $-1,41(50: 50)$ & $0(1,0)$ \\
6 & $+1,41(100: 0)$ & $0(1,0)$ \\
7 & $0(75: 25)$ & $-1,41(0,0)$ \\
8 & $0(75: 25)$ & $+1,41(2,0)$ \\
9 & $0(75: 25)$ & $0(1,0)$ \\
10 & $0(75: 25)$ & $0(1,0)$ \\
11 & $0(75: 25)$ & $0(1,0)$ \\
\hline
\end{tabular}

A elaboração dos filmes seguiu os seguintes passos:

- Pesou-se a concentração de glicerol definida pelo planejamento para cada ensaio;

- Solubilizou-se em $100 \mathrm{~mL}$ de água destilada, com agitação de $900 \mathrm{rpm}$, por 15 minutos;

- Adicionou-se 1,5 g dosbiopolímeros (1,5\% p/valginato+pectina) de acordo com as proporções definas pelo planejamento;

- A solução foi aquecida e mantida $a 40^{\circ} \mathrm{C}$ durante 1 hora para solubilização dos filmes e préreticulação;

- A pré-reticulação foi realizada com adição de $7,5 \mathrm{~mL}$ de $\mathrm{CaCl}_{2} \cdot 2 \mathrm{H}_{2} \mathrm{O}(1,0 \%$ p/v), utilizandose uma bomba peristáltica com vazão de $1,0 \mathrm{~mL} / \mathrm{min}$;

- O gel formado foi centrifugado durante 2 minutos a $40^{\circ} \mathrm{C}$ e $4000 \mathrm{rpm}$, para retirada das bolhas;

- A solução foi transferida em alíquotas de 50 g para placas de acrílico (15x 15cm);

- As placas foram levadas à secagem em estufa de circulação de ar a $40^{\circ} \mathrm{C}$ por 20 horas;

- Após a secagem os filmes foram armazenados por 48 horas à temperatura ambiente $(23 \pm$ $2^{\circ} \mathrm{C}$ ), com umidade relativa de $52 \%$;

- Para a $2^{\circ}$ reticulação os filmes foram imersos em $50 \mathrm{~mL}$ de uma solução de $\mathrm{CaCl}_{2} \cdot 2 \mathrm{H}_{2} \mathrm{O}$ $(5,0 \% \mathrm{p} / \mathrm{v})$ e glicerol $(3,0 \% \mathrm{p} / \mathrm{v})$, por 20 minutos (condições definidas por Bierhalz, 2010);

- Foi realizada uma nova secagem em estufa de circulação de ar a $25^{\circ} \mathrm{C}$ por 5 horas;

- Após a secagem os filmes foram armazenados por $72 \mathrm{~h}$ à temperatura ambiente $\left(23 \pm 2^{\circ} \mathrm{C}\right)$, com umidade relativa de $52 \%$, antes da realização das caracterizações. 
Na melhor condição experimental obtida a partir dos ensaios de planejamento fatorial, foi adicionado um concentrado de células de Lactobacillus caseina solução de pré-reticulação $\operatorname{de~} \mathrm{CaCl}_{2}(1 \% \mathrm{p} / \mathrm{v})$.

\subsection{Caracterização dos Filmes}

Aspectos visuais: Foram considerados os aspectos visuais e táteis para selecionar as formulações mais promissoras. Todas as avaliações foram realizadas pelo mesmo avaliador. Os aspectos avaliados foram homogeneidade e continuidade (ausência de partículas e de rupturas ou regiões quebradiças), flexibilidade, adesividade (grau de aderência) e facilidade de desprendimento do suporte.

Umidade: A determinação do conteúdo de umidade foi realizada por gravimetria, com análises em duplicata, utilizando-se a secagem em estufa a $105^{\circ} \mathrm{C}$ até peso constante (INSTITUTO ADOLFO LUTZ, 1985).

Solubilidade: A massa solúvel (MS) em água dos filmes foi quantificada segundo método proposto por Irissin-Mangataet al. (2001), com análises em duplicata. Inicialmente, a umidade de uma amostra de cada filme foi determinada. Outra amostra do mesmo filme foi imersa em $50 \mathrm{~mL}$ de água destilada e o sistema mantido sob agitação lenta e periódica (150 $\mathrm{rpm}) \mathrm{a} 25^{\circ} \mathrm{C}$ por 24 horas. Após esse período o material não solúvel foi filtrado (filtro $40 \mu \mathrm{m}$ ) e seco em estufa a $105^{\circ} \mathrm{C}$ até peso constante. A MS foi expressa em função da massa seca inicial conforme a Equação 1:

$$
M S=\frac{\left[m_{0}(1-\omega)\right]-m_{f}}{m_{0}(1-\omega)}
$$

Onde: $M S$ - massa solúvel em água ( $\mathrm{g} / \mathrm{g}$ filme seco); $\mathrm{m}_{\mathrm{o}}-$ massa total inicial de amostra $(\mathrm{g}) ; \mathrm{m}_{\mathrm{f}}$ - massa não solúvel $(\mathrm{g}) ; \omega$ - fração de umidade em base úmida ( $\mathrm{g}$ água/g filme).

Grau de intumescimento: Foi determinado segundo a metodologia proposta por Xuet al.(2003), com análises em duplicata. A massa de uma amostra de cada filme $(2,0 \times 2,0$ $\mathrm{cm})$ foi quantificada, disposta em uma placa de Petri e imersa em água destilada, pesando-se amostras individuais para cada tempo $(1,3,5,10,15,20,30,40,50$ e $60 \mathrm{~min})$.Posteriormente, os filmes foram enxugados utilizando-se papel absorvente, tendo-se o cuidado para não pressionar o filme, e novamente pesados, determinando-se a massa do filme úmido. O grau de intumescimento (GI) foi determinado segundo a Equação 2:

$$
G I=\frac{m_{u}-m_{i}}{m_{i}}
$$

Onde: $\mathrm{GI}$ - grau de intumescimento; $\mathrm{m}_{\mathrm{u}}$ - massa do filme úmido $(\mathrm{g}) ; \mathrm{m}_{\mathrm{i}}-$ massa total inicial da amostra $(\mathrm{g})$.

Contagem de micro-organismos: A avaliação dos micro-organismos probióticos viáveis foi realizada pela contagem de unidades formadoras de colônias (UFC), retirando-se amostras dos filmes prontos diluindo-se em citrato de sódio $1,5 \%$ (p/v), seguido de diluição seriada em solução salina $0,85 \%(\mathrm{p} / \mathrm{v})$. Alíquotas foram plaqueadas em meio MRS Ágar (adicionado de $2 \% \mathrm{p} / \mathrm{v}$ de glicose) e cultivados pela técnica de pour-plate por $72 \mathrm{~h} \mathrm{a} 37^{\circ} \mathrm{C}$. 


\section{RESULTADOS E DISCUSSÕES}

Para análise do planejamento experimental foram estabelecidas como variáveis respostas o GI e a MS, tendo como condições ótimas os menores níveis destas variáveis, pois se espera obter filmes com baixos níveis de absorção de água e boa resistência à solubilidade. As superfícies de resposta para as variáveis GI e MS são mostradas nas Figuras 1-A e 1-B, respectivamente.
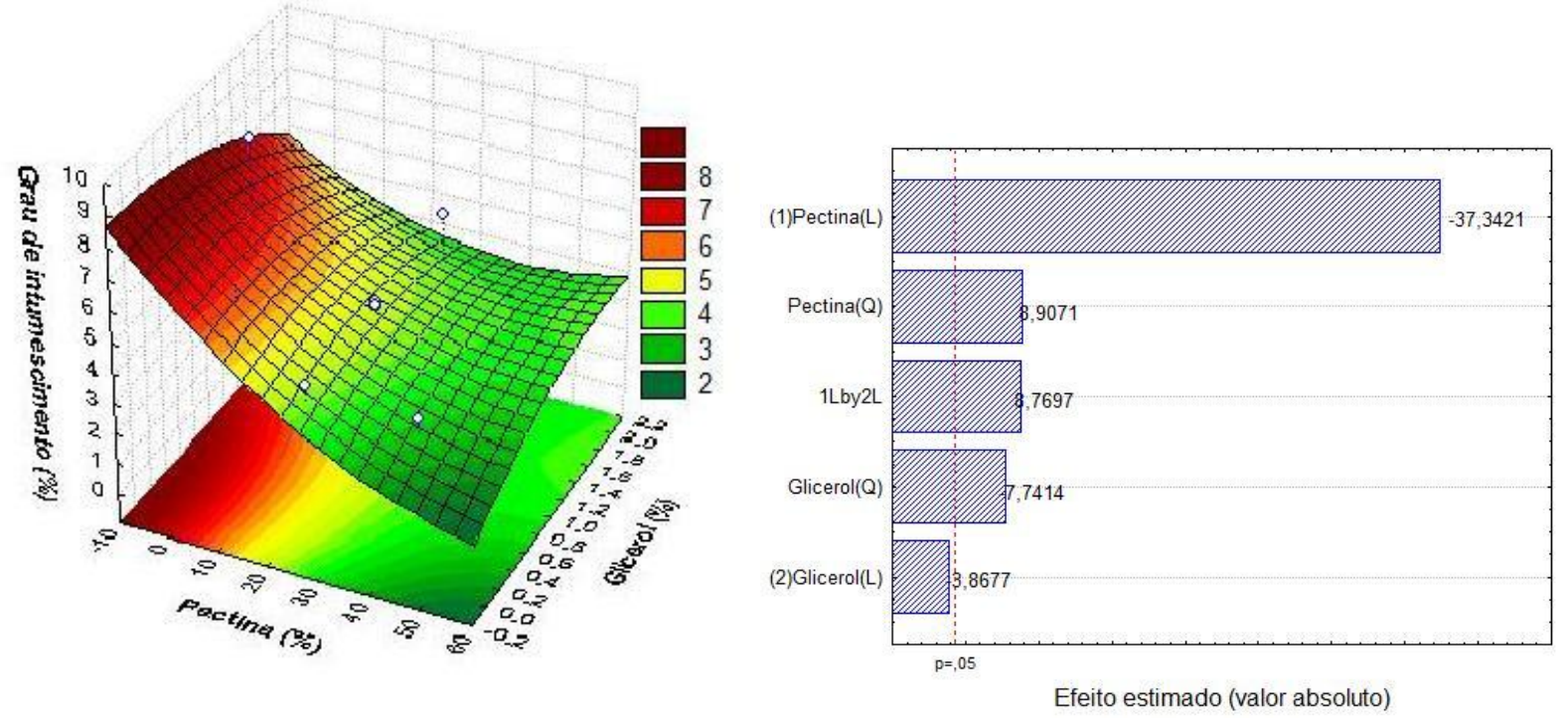

Figura 1 - (A) Superfície de resposta e (B) Gráfico de Pareto para a variável grau de intumescimento (GI).
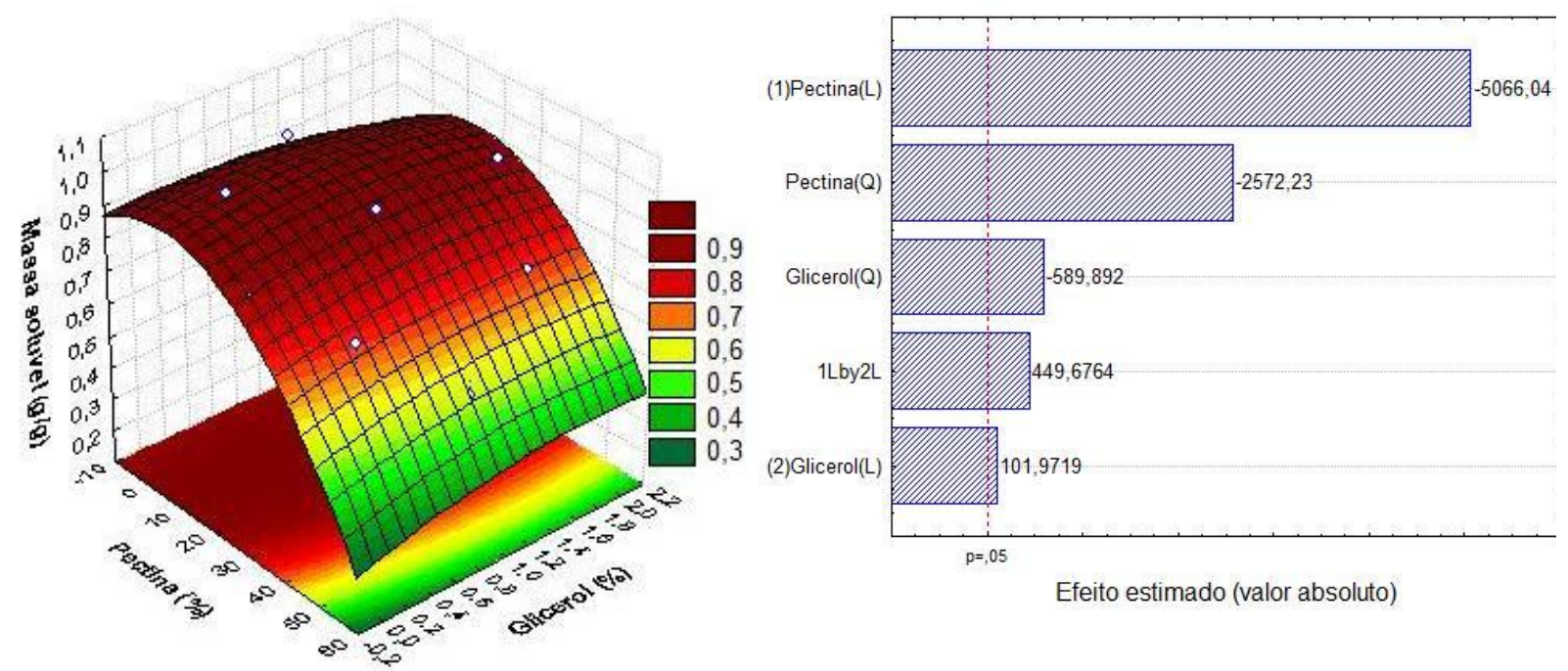

Figura 2 - (A) Superfície de resposta e (B) Gráfico de Pareto para a variável massa solúvel (MS). 
Como podemos observar, os menores níveis de GI e MS foram obtidos nas maiores proporções de pectina. A Figura 1-A mostra que menores valores de GI podem ser obtidos com menores níveis de glicerol. No entanto, a análise estatística dos dados apresentada pelos gráficos de Pareto nas Figuras 1-B e 2-B para as duas variáveis mostra que essa variável tem pouca significância estatística.

Os níveis de alginato e pectina, testados no planejamento com máximo de $50 \%$ de pectina, foram definidos com base nos resultados de Bierhalz (2010), onde a autora descreve que filmes obtidos com maiores proporções de alginato e menores de pectina apresentaram menor conteúdo de umidade e menor solubilidade em água, o que está relacionado à maior hidrofilicidade da pectina. Já nossos resultados apresentaram efeito contrário, onde menores proporções de alginato e maiores de pectina proporcionaram a obtenção de filmes mais resistentes à solubilidade em água e com menor GI. Com base nos resultados do presente trabalho, foi selecionado o ensaio 5 como a melhor condição para a inserção dos microorganismos probióticos, isto devido ao fato de ter apresentado a menor MS e o menor GI.

Os aspectos visuais foram analisados pela atribuição de notas de 0 a 10 para cada aspecto dos filmes, comparando-se os 11 ensaios obtidos pelo planejamento, além do ensaio 12 que é a repetição do ensaio 5 contendo os micro-organismos probióticos. Na avaliação desses atributos também foi possível perceber que as maiores concentrações de pectina possibilitaram a obtenção de filmes com melhor homogeneidade e continuidade, com ausência de rupturas, e apesar da menor flexibilidade, apresentaram baixa adesividade, o que facilita o manuseio dos filmes.

A Figura 3 apresenta o GI em função do tempo, observando-se um aumento na absorção de água com o aumento da concentração de alginato. Inicialmente ocorre uma maior absorção de água em todos os ensaios, e ao final dos 60 minutos todos os ensaios apresentam-se praticamente estáveis. O GI após o tempo de 60 min variou entre 3,15 para o ensaio 5 com o maior percentual de pectina $(50 \%)$ e 8,85 para o ensaio 6 onde temos apenas alginato.

As diferentes concentrações de glicerol utilizadas na formulação dos filmes não apresentaram influência no aumento do GI, apesar de Silva et al. (2009) terem demonstrado esse efeito. Esses autores, trabalhando com 1,5\% de biopolímeros para produção de filmes de alginato e pectina $(50 \% / 50 \%)$, com diferentes concentrações de cálcio na primeira reticulação, demonstraram que o aumento da concentração de glicerol diminuiu o GI dos filmes. Os autores também compararam filmes simples de pectina e alginato, onde observaram maior GI nos filmes simples de pectina, resultados semelhantes aos de Bierhalz (2010), que também observou maior GI nos filmes com maior concentração de pectina. 


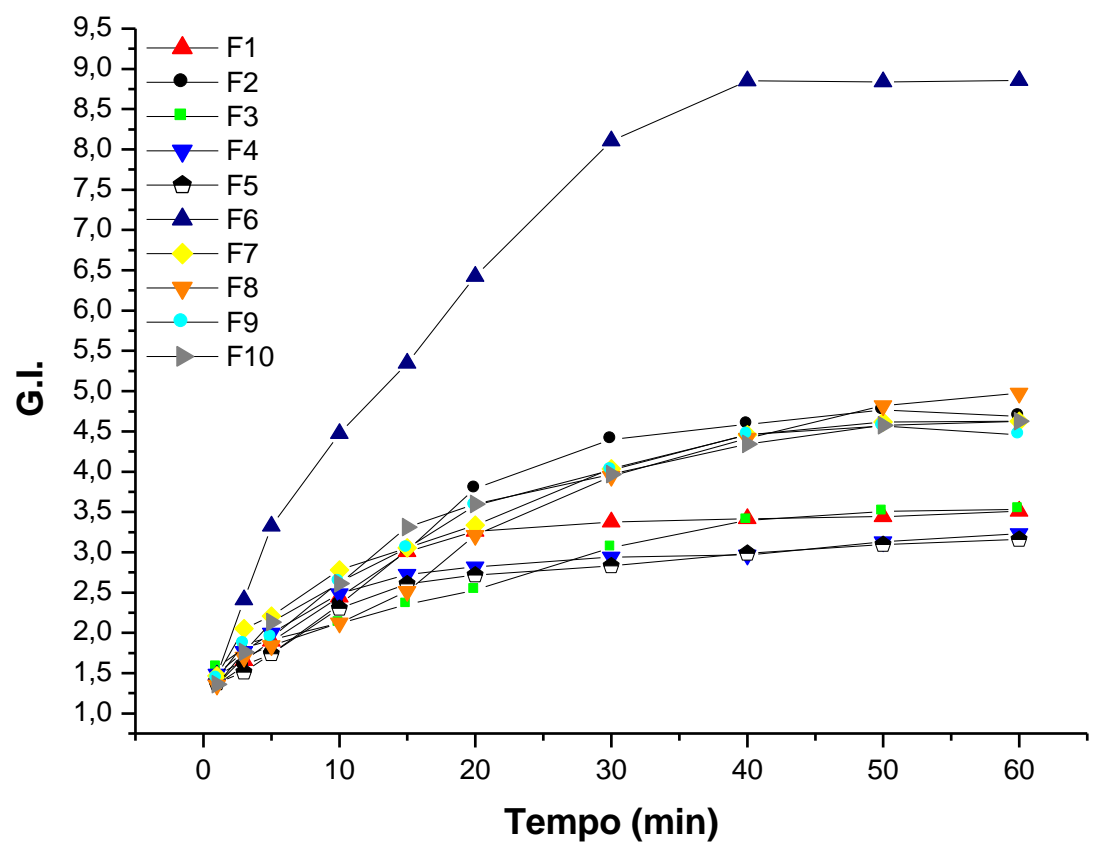

Figura 3 - Curva do grau de intumescimento dos 11 ensaios do planejamento experimental.

As divergências nos nossos resultados de solubilidade em relação aos resultados encontrados na literatura podem em parte ser atribuídos às diferenças estruturais encontradas nos biopolímeros. Dependendo do tipo de alga em que o alginato é extraído podemos encontrar diferentes proporções entre as unidades de ácido manurônico (M) e gulurônico $(\mathrm{G})$ (Clare, 1993apudBierhalz, 2010). Os alginatospoli-G são mais reativos com os íons $\mathrm{Ca}^{++}$, pois estas cadeias apresentam formato retorcido que favorece a presença de cavidades adjacentes, nas quais se situam os íons cálcio (Andrade et al., 2008). Géis com maior quantidade de blocos $G$ são duros e costumam apresentar alto valor de tensão na ruptura e grande estabilidade térmica, enquanto que o aumento dos blocos $M$ favorece a formação de géis macios, flexíveis e com poros pequenos. Outro fator relevante que pode ter influenciado nos resultados de solubilidade diz respeito às alterações na temperatura de reticulação dos filmes, visto que se trabalhou com temperatura de reticulação de $40{ }^{\circ} \mathrm{C}$. Esta alteração foi necessária para a incorporação dos micro-organismos probióticos que foi realizada nessa etapa. Segundo Pavlath e Robertson (1999), são necessárias temperaturas de reticulação acima de $50^{\circ} \mathrm{C}$ para que as soluções apresentem viscosidade adequada.

Os filmes probióticos apresentaram contagens de $10^{12} \mathrm{UFC} / \mathrm{g}$, desta forma podendo ser empregados como embalagens probióticas em alimentos. Segundo a legislação brasileira (ANVISA, 2008), os alimentos probióticos devem conter um número de células entre $10^{8}$ a $10^{9}$ UFC na recomendação de consumo diária. Na literatura apenas foi encontrado o trabalho de Tapiaet al. (2007), que verificou em filmes de alginato e gelana adicionados do probióticoBifidobacterium valor de contagem inferior ao encontrado nesta pesquisa $\left(10^{10}\right.$ $\mathrm{UFC} / \mathrm{g}$ ). 


\section{CONCLUSÕES}

Podemos concluir que o estudo das diferentes proporções de alginato/pectina e glicerol, através de planejamento fatorial, possibilitou a seleção de uma formulação com alto teor de pectina, adequada para inserção de L. casei como micro-organismo probiótico, apresentando baixa solubilidade e baixo grau de intumescimento. Os filmes obtidos também podem ser considerados um bom veículo carreador de micro-organismos probióticos, apresentando contagens de $10^{12} \mathrm{UFC} / \mathrm{g}$, o que possibilita sua classificação como alimento probiótico segundo a legislação brasileira.

\section{REFERÊNCIAS}

ANDRADE, S.A.C.; GUERRA, T.M.B.; RIBEIRO, M.A.; GUERRA, N.B. Emprego derevestimentos comestíveis de alginato e pectina de baixa metoxilação em alimentos: Revisão. B. CEEPA, v.26, n.1, p.41-50, 2008.

ANVISA. Ministério da Saúde. Agência Nacional de Vigilância Sanitária. IX-Lista de Alegações de Propriedade Funcional Aprovadas. Diário Oficial [da] República Federativa do Brasil, Brasília, julho de 2008.

BIERHALZ, A.C.K. Confecção e caracterização de biofilmes ativos à base de pectina BTM e de pectina BTM / alginato reticulados com cálcio. Dissertação de Mestrado, Engenharia Química - UNICAMP, Campinas - SP, 2010.

BURITI, F.C.A.; SAAD, S.M.I.; Bactérias do grupo Lactobacillus casei: caracterização, viabilidade como probióticos em alimentos e sua importância para a saúde humana.Archivos Latinoamericanos de Nutricion, v.57, n.4, 2007.

INSTITUTO ADOLFO LUTZ. Métodos Químicos e Físicos para análise de alimentos. Normas Analíticas do Instituto Adolfo Lutz, 3 ed., v.1, São Paulo: IMESP, 1985, 288p.

IRISSIN-MANGATA, J.; BAUDUIN, G.; BOUTEVIN, B.; GONTARD, N. New plasticizers for wheat gluten films. European Polymer Journal, v.37, p.1533-1541, 2001.

PAVLATH, A.E., ROBERTSON, G. H. Biodegradable polymers vs. recycling: what are the possibilities. Critical Reviews in analytical Chemistry, v.29, p.231-241, 1999.

SILVA, M.A.; BIERHALZ, C.A.K.; KIECKBUSCH, T.G. Alginate and pectin composite films crosslinked with $\mathrm{Ca} 2+$ ions: Effect of the plasticizer concentration. Carboh.Polym., v.77, p.736-742, 2009.

TABOADA, O.M; CARVALHO, R.A.; SOBRAL, P.J. Análise dinâmico-mecânica: aplicações em filmes comestíveis. Quím. Nov., v.31, n.2, p.384-393, 2008.

TAPIA, M.S.; ROJAS-GRAÜ, M.A.; RODRÍGUEZ, F.J.; RAMÍREZ, J.; CARMONA, A.; MARTIN-BELLOSO, O. Alginate and Gellan Based Edible Films for Probiotic Coatings on Fresh-Cut Fruits. Journal of Food Science, v.72, n.4, p.190-196, 2007.

XU, J.B.; BARTLEY, J.P.; JOHNSON, R.A. Preparation and characterization of alginatecarrageenan hydrogel films crosslinked using a water-soluble carbodiimide (WSC). J. of Memb. Scien., v.28, n.2, p.131-146, 2003.

YANG L.; PAULSON A.T. Mechanical and water vapor barrier properties of edible gellan films. Food Res Intl., v.33, p.563-70, 2000.

ZACTITI, E.M.; KIECKBUSCH, T.G. Processo de produção de filmes plásticos ativos biodegradáveis de alginato de cálcio de baixa solubilidade. Pedido de Privilégio de Patente. INPI, Prot. 01850064015 - 12/2005. 